\title{
Las tablas de Luis de Morales en el retablo de la iglesia de San Martín de Plasencia (Cáceres)
}

\author{
Jesús Manuel López Martín
}

Se trata de un retablo de talla dorada y policromada de estilo plateres$\mathrm{co}^{1}$. Se compone de predela o banco, tres cuerpos donde alternan los recuadros con pintura sobre tabla de Luis de Morales y su taller, y los escultóricos de la calle principal, del maestro entallador Francisco Rodríguez.

Hay cinco recuadros en cada uno de los tres cuerpos. Los de los extremos ocupados por las pinturas en tabla, que son seis, más dos apaisadas de la predela. Las hornacinas están ocupadas por imágenes de talla, con técnica de estofado, realizada por los pintores Diego Pérez de Cervera y Antonio Pérez, en un total de ocho.

El retablo está coronado por una venera que cobija al Padre Eterno en posición de bendecir. A ambos lados aparece la heráldica del prelado promotor y mecenas del retablo, Gutiérre Vargas Carvajal, obispo de la ciudad.

\section{EL RETABLO}

Fué encargado por el propio prelado Gutiérre de Vargas Carvajal al entallador Francisco Rodríguez, natural y vecino de Plasencia. Su comienzo

1 Sobre el tema puede consultarse: GaYA NuÑo, J.A.: Luis de Morales, CSIC, Madrid 1961. Solis Rodríguez, Carmelo: Luis de Morales, Badajoz, 1977. "Luis de Morales», Rev. de Estudios Extremeños, 1978, págs. 49/137. Pérez SánCHEZ, A.E.: El retablo de Morales en Arroyo de la Luz, Catálogo Exposición del Ministerio de Cultura, Madrid, 1974. MARIAS, F.: Luis de Morales. «EI Divino». Colec. Cuadernos de Arte Español, $n^{\circ}$ 68. Historia 16. LOPEZ MARTiN, J.M.: El retablo de la Iglesia de San Martín de Plasencia. Consejería de Cultura. Plasencia, 1979. LóPEZ MARTín y otros: El retablo de Luis de Morales en la Iglesia de San Martín de Plasencia. (Vídeo.) Inédito, 1993. Así como el Archivo de la Iglesia de San Esteban («Libros de Cuentas de la Iglesia de San Martín»): Libro de Cuentas 1562 a 1565. Libro de Cuentas 1566, 1567, 1569, 1570, 1571, 1575, 1576, 1577. 
está fechado en el año 1557. Con la muerte del obispo en el año 1559, la progresión de la obra se ralentiza de tal manera que en el año 1560, se decide no abonar cantidad alguna al entallador "hasta retocar y enmendar lo que por tasación se había dispuesto». La finalización estaría entorno al año 1566, cuando se abonaron a Francisco Rodríguez los últimos 3.302 mrvs. que aún se le debían de la talla del retablo y se debió desmontar para doraile.

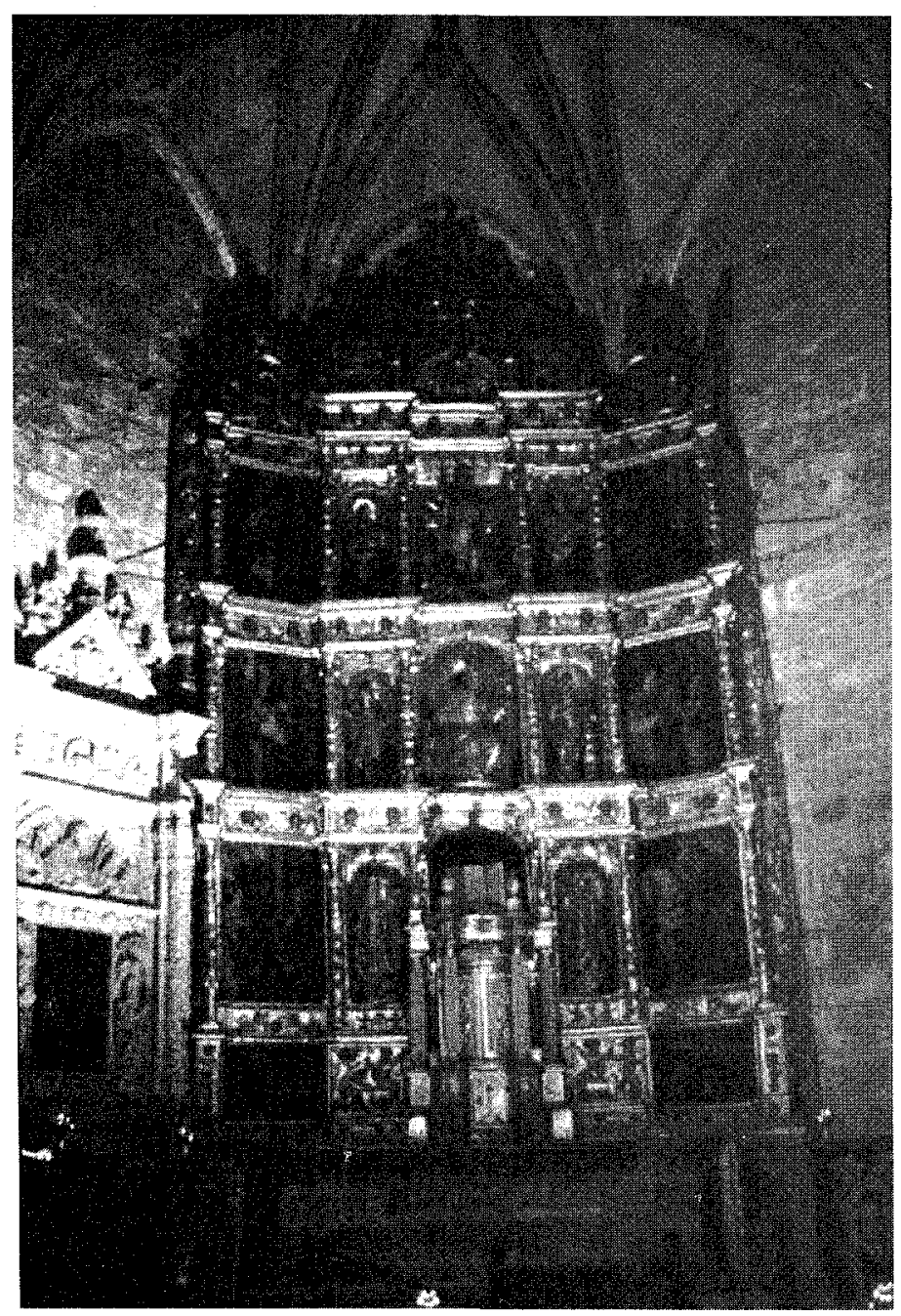

Fig. 1. 
La caja y decoración de los grutescos responden a los modelos de los retablos platerescos tan del gusto del prelado Vargas Carvajal, hombre entendido en arquitectura e ilustrado en sus conocimientos culturales. Sin duda existe cierta similitud con el de la "Capilla del Obispo", Capilla/Mausoleo de la familia Vargas en Madrid, y en algunos esquemas de grutescos existentes en las Portadas Norte, Meridional y de la Sacristía de la Catedral de Plasencia, a la que dio un gran impulso en la progresión de las obras.

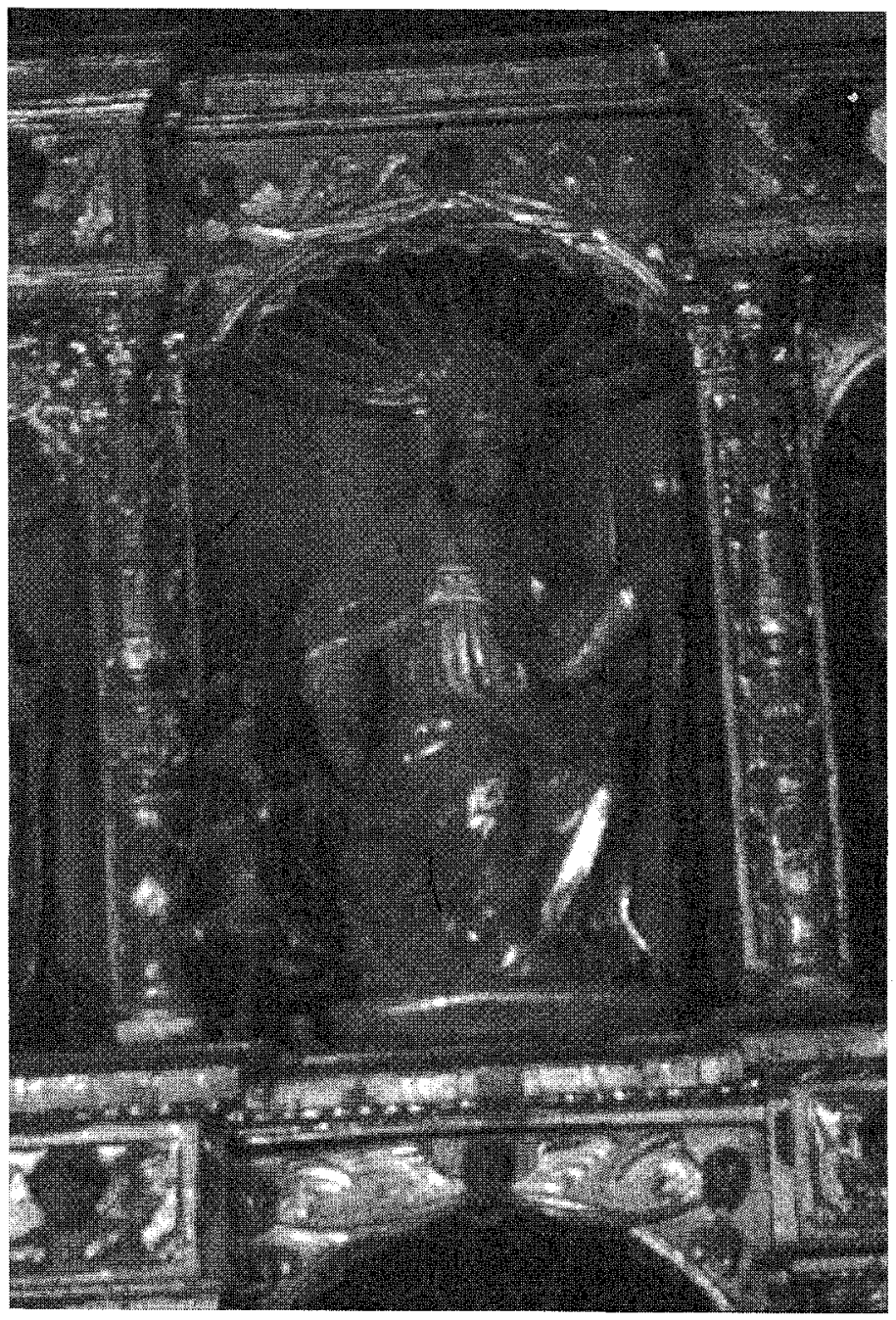

Fig. 2. 


\section{LAS ESCULTURAS}

Las esculturas, al menos las de la calle principal serían realizadas por el entallador Francisco Rodríguez. Sabemos que en el año 1558 el mismo obispo Vargas Carvajal dispuso que el entallador hiciese la imagen de San Martín, como obispo de Tours, y que terminada ésta continuase la obra del retablo. En el resto de las esculturas sería ayudado por el maestro carpintero Baltasar García que entonces realizaba unas andas para la iglesia.

Las esculturas de la calle inferior, a falta de la del hueco central por estar ocupado por un tabernáculo/expositor del Santísimo son: la de la izquierda representa a Santa Catalina, acompañada de los atributos de su martirio, rueda con cuchillo y espada, y la de la derecha, a San Lorenzo, que lleva en sus manos un libro y la parrilla. En el cuerpo medio, ocupa la hornacina central y mayor, la imagen del santo titular de la parroquia, San Martín, obispo de Tours, revestido de pontifical, con mitra y báculo, sentado, y a su lado un pobre cojo, al que da limosna. En las hornacinas de los lados, San Juan Apóstol, en su clásica iconografía de hombre imberbe y melancólico y Santa Bárbara, acompañada de la Torre de los Truenos. En el último cuerpo, dentro del recuadro central, se representa la Resurrección de Cristo, el cual aparece con manto y aureola de rayos, bendiciendo y en pie sobre el sepulcro que guarda un soldado. En las hornacinas de los lados se ven las estatuas de San Pedro, con las llaves del cielo y de la tierra y un santo obispo, posiblemente se trate de San Blas, obispo de Sebaste y titular de la única cofradía de esta iglesia.

\section{DORADO Y ESTOFADO DEL RETABLO}

El estofado y dorado del retablo fue realizado despủés de morir el obispo promotor. Las primeras entregas de maravedíes al pintor Diego Pérez de Cervera, vecino de Plasencia, son los 6.000 mrvs. del año 1560, a los que siguen 34.000 mrvs., en 1562; la misma cantidad en 1566; 114.000 mrvs. y 40 fanegas de trigo en 1567; 9.000 mrvs. en 1570; 29.774 mrvs. en $1571 ; 28.598$ en $1575 ; 43.697$ mrvs. en 1576. De manera que su realización abarcaría desde la carta de tasación del año 1569, y la del año 1577 cuando volvió a ratificar su anterior declaración y afirmaba que él "pintó, doró y estofó" el retablo de San Martín. El precio total ascendió a la cantidad de 350.000 mrvs. En la obra fue ayudado por su hermano Antonio Pérez.

En la actualidad el retablo ofrece una doble policromía, la perteneciente al siglo XVI, que ha sido tapada por otra de los siglos XVIII o XIX y que es 
la que se observa. Por esta razón la policromía y estofado originales han quedado tapados, y al tratarse de una capa gruesa ha desvirtuado no sólo la riqueza cromática, sino también los detalles de los relieves de «puttis» y grutescos.

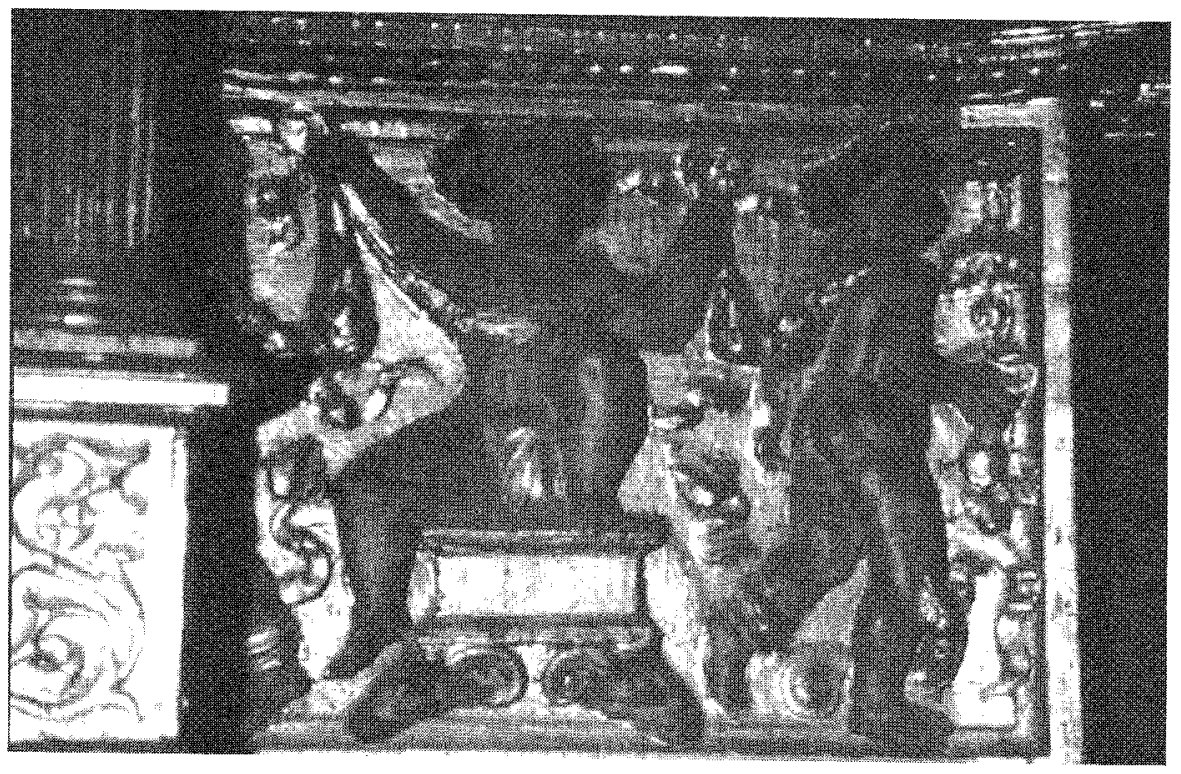

Fig. 3.

\section{LAS TABLAS DE LUIS DE MORALES}

En la elección de Luis de Morales como pintor de las tablas para nada participó el prelado promotor del retablo que ya había fallecido en 1559. Posiblemente la idea del prelado hubiera sido utilizar relieves en vez de pinturas, como solía ser el modelo habitual en sus obras como mecenas de retablos.

Las tablas, soporte de las pinturas, fueron llevadas a Arroyo del Puerto (hoy de la Luz) en el año 1565, sin duda porque estaba ocupado Luis de Morales en el retablo mayor de la Iglesia parroquial.

Las tablas pintadas representan los «Misterios de la Virgen»: la Encarnación, la Visitación, la Natividad, la Epifanía, la Circuncisión, más San Martín a caballo, partiendo su capa con el pobre. Las tablas de la predela se corresponden con los Santos Padres: San Jerónimo y San Agustín. El importe total de las tablas de Morales fue de 56.200 maravedíes. 
Las medidas de las tablas es de $85 \times 125 \mathrm{cms}$., menos las dos del sotobanco que tienen $80 \times 55 \mathrm{cms}$. La madera es de nogal y cada uno de los recuadros suelen estar formados por dos o tres tablas. La técnica utilizada es mixta de pintura al temple y al aceite, utilizando como base de imprimación la cola de animal con sulfato de cal.

\section{1. «La Anunciación»}

Es un tema varias veces interpretado por Morales (Catedral de Badajoz, Arroyo de la Luz, Museo del Prado), ofrece aquí una versión con claras diferencias con las anteriores y de sumo interés, por presentar algunos elementos que nos permiten asomarnos a su modo de trabajar.

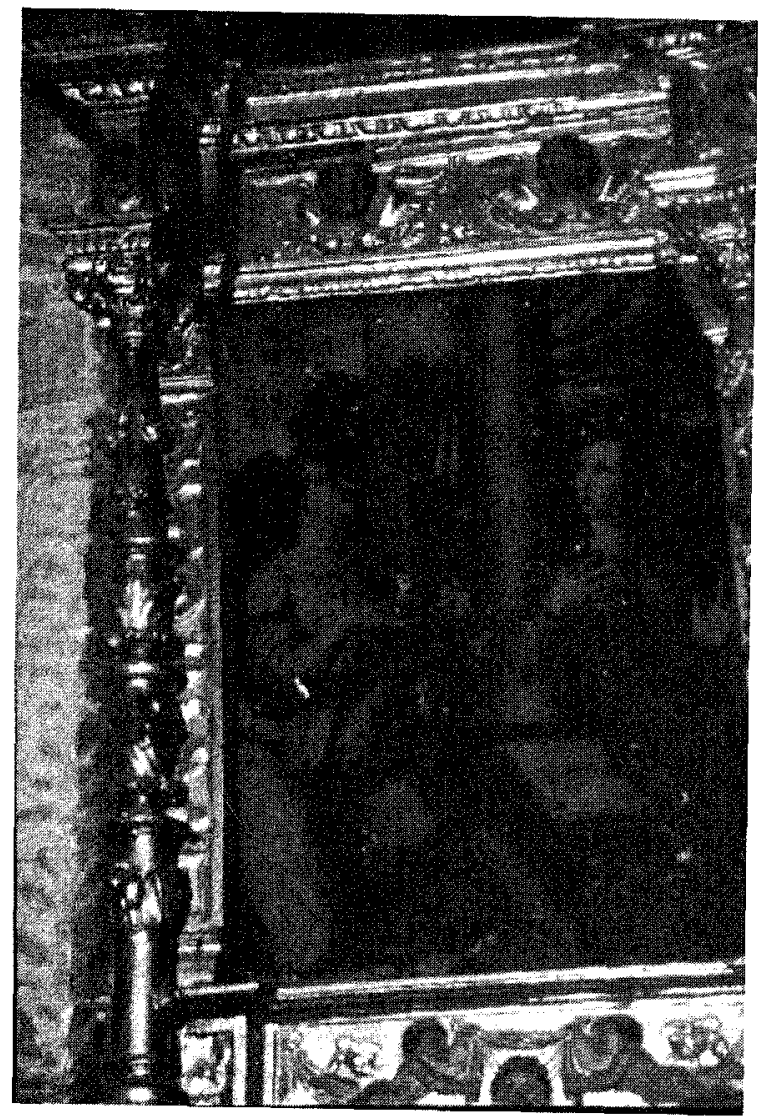

Fig. 4. Anunciación. 
La actitud del Angel semiarrodillado. El brazo derecho doblado y la mano extendida a diferencia del de Arroyo, que está erguido y en posición de señalamiento. La mano izquierda en ambas composiciones, sostiene el cetro que, inclinado acompaña su movimiento, y las líneas fundamentales del vestido, que resulta ser una túnica de lino blanco, simple en textura y planimétricamente continuado en los plegamientos.

También la actitud de la Virgen, semiarrodillada ante el reclinatorio, levanta la mirada hacia el Espíritu Santo y abre sus manos en un claro ejemplo de ofrecimiento pleno al misterio de la Encarnación. Frente a estas formas, la Virgen de Arroyo, inclina la cabeza, entorna los ojos en posición de humildad, y junta las manos, siguiendo una inspiración de estampa tizianesca. El vestido es el habitual con la túnica gris azulada y los tonos rojo/carminoso de su manto.

La Paloma del Espíritu Santo, es interpretada con modelo convencional y análogo a varias de sus versiones.

Igual sentido común mantienen las naturalezas muertas: las azucenas simbólicas han ocupado un amplio espacio y centran la composición ahora, elegantemente dispuestas en ágil silueteado caligráfico; no existe en la tabla de San Martín cestillo alguno de costura, que en Arroyo fue sustituido por una arquilla decorada con herrajes, y cerrada, alusiva muy probablemente a la virginidad de María, como «arca sellada».

Se ofrece un sistema compositivo de tipo piramidal, cuyo vértice superior está marcado por el Espíritu Santo, y los extremos por las figuras del Angel y la Virgen. Esta figuración geométrica es reforzada por otra de proyección vertical: el estandarte del baldaquino, y la pilastra de la ventana que separan plásticamente ambas figuras; y otra oblicua: por un libro y el reclinatorio.

La tabla, sin duda, salió de las manos del maestro dejando escasa participación a su taller.

\section{2. "La Visitación»}

Asunto poco frecuente en el repertorio de Morales, pero necesario en este caso al tratarse el ciclo de María. Es una de las mejores tablas del retablo y sin duda la que confiere el sello más característico de su estilo.

La composición está centrada en las figuras de la Virgen y Santa Isabel que mantienen una tensión propia del Cuatrocientos italiano, señalada por la diferencia de edad, actitudes y gestos de ambas mujeres: la 


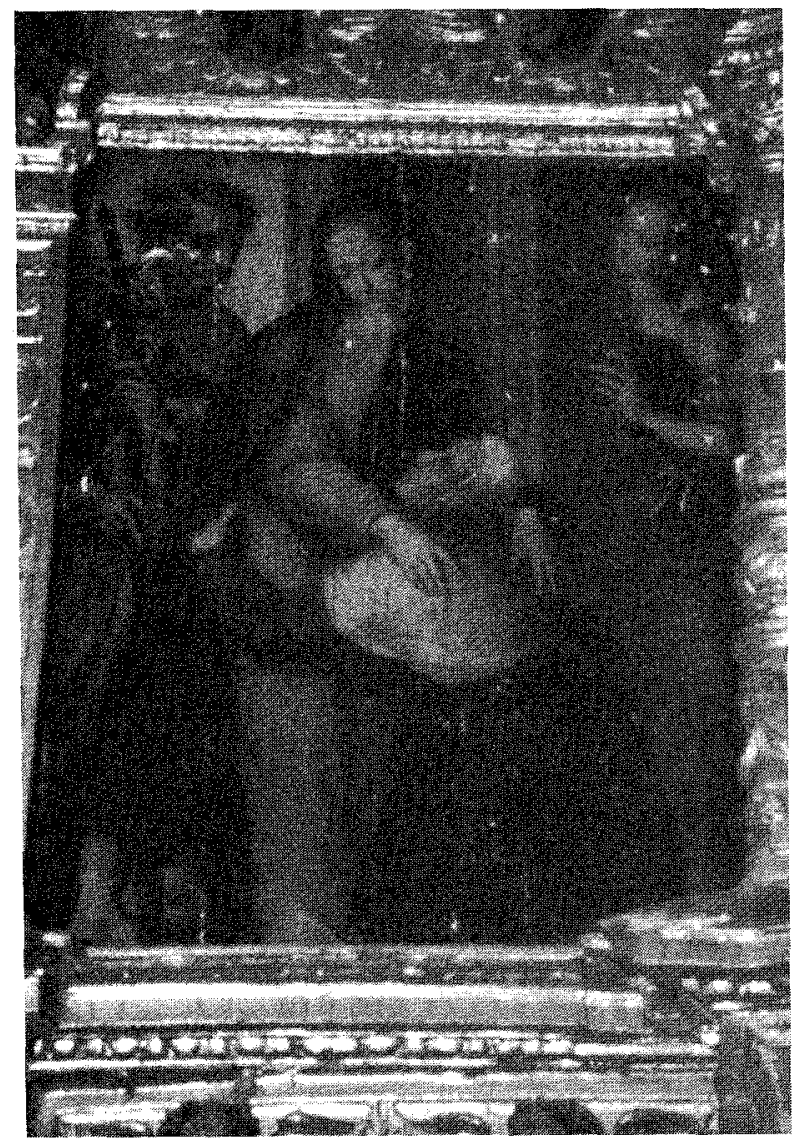

Fig. 5. Visitación.

Virgen erguida, inclinada la cabeza, entorna y baja los ojos y levemente gira la cabeza, apartándola de la mirada incisiva y el rostro pasionista de su Prima, que arrodillada se abraza al vientre de María.

La escena está enmarcada por la figura de una doncella, que con ademanes delicados aparece como espectadora. Observa el hecho a través de la esquina de una pilastra, admirablemente decorada con grutescos y formas «acandelieri»; y la figura de Zacarias, hombre de tez oscura y cabello alborotado semejante al San José de la Adoración de los Pastores de Arroyo, que recuerdan algunas de las interpretaciones de Pieter Coecke van Aelst.

En la composición domina la línea diagonal marcada por las figuras de Zacarías y Santa Isabel; al tiempo que se ofrece una horizontal superior 
concomitante con el isocefalismo. La centralidad ha sido reforzada por la línea vertical de las arquitecturas.

\section{3. «La Natividad»}

Sólo se conoce otra interpretación moralesca de este asunto, la de Arroyo de la Luz, compuesta con esquema totalmente diferente, pero mostrando idéntica derivación de modelos italianos en la composición del grupo y de tipos flamencos en los personajes.

El gesto y disposición de la Virgen mantiene rasgos comunes de manos unidas y caída de párpados, muy diferentes a los bassanescos de Arroyo. San José es un anciano tranquilo que habla con el movimiento de las

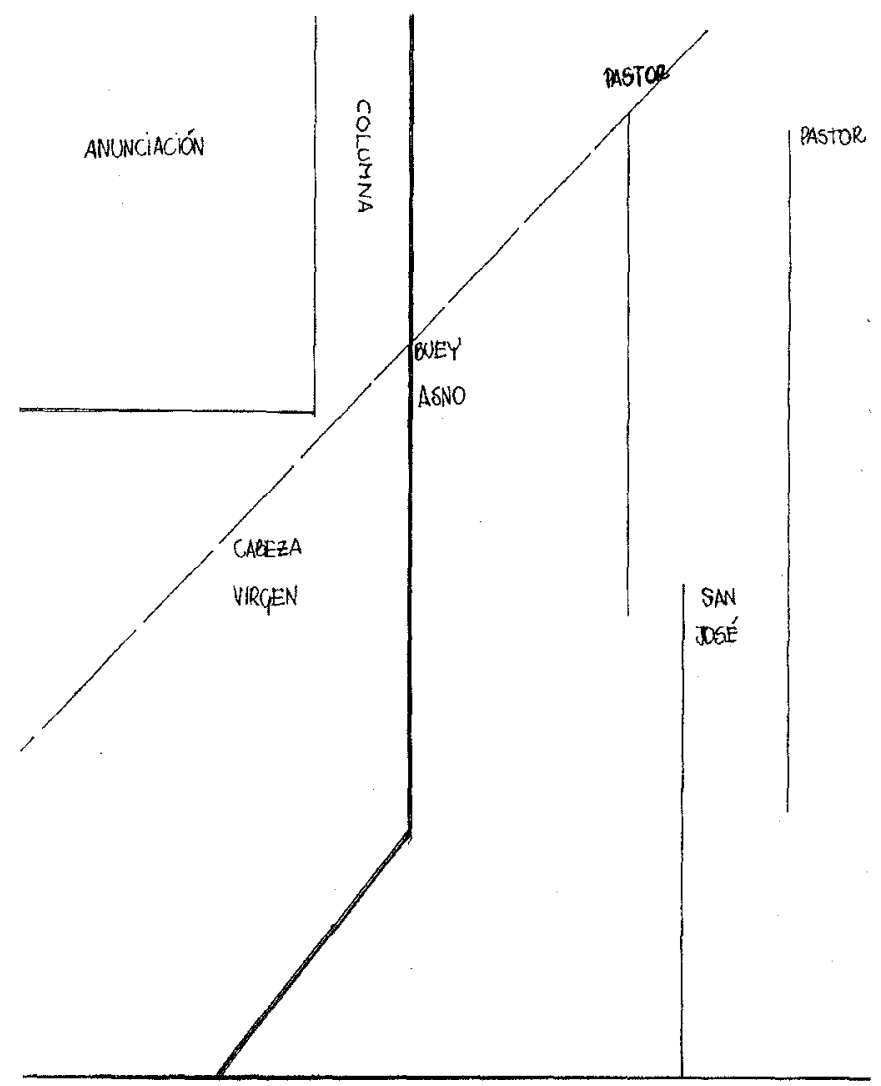

Fig. 6. Estructura de la composición de la Anunicación de los Pastores. 
manos y mantiene un rostro de serenas facciones y delicado cabello. Los pastores, aparecen, en segundo término, en un abierto diálogo y donde uno de ellos levanta una de sus manos en actitud de señalar la Estrella Divina, gesto similar al del Angel de la Anunciación de Arroyo. Sorprende, según Pérez Sánchez, la falta de interés de Morales por el efecto luminoso, con el Niño Jesús visto como foco incandescente, que ilumina a cuantos a él se acercan, y que interesó, en grado máximo al Greco y a los "pretenebristas» de las generaciones siguientes.

Morales pertenece aquí, como en toda su obra, fiel a la difusa luz del manierismo romanista, a sus colores claros y lunares y al modelo esfumado de tradición leonardesca.

La estructura de la composición viene dada por distintas líneas representativas: una diagonal marcada por la figuras de la Virgen, animales del pesebre y uno de los pastores; y tres verticales, las correspondientes a los pastores y a San José. En el extremo superior se utiliza el recurso flamenco de narrar varias secuencias del hecho representado, en este caso «La anunciación a los pastores».

En esta tabla, a diferencia de las anteriores, domina el trabajo del taller sobre los retoques del maestro.

\section{4. «La adoración de los Reyes»}

Tema repetido en la obra de Morales, conocemos hasta cuatro versiones (Plasencia; Cáceres: colección López Montenegro; Catedral de Badajoz, San Salvador de Elvas y Arroyo de la Luz), todas muy diversas, en composición y tipos, a la de Plasencia.

Esta, compuesta de modo tradicional, posee cierta similitud con la de Arroyo que es más severa en perfección y equilibrio. La Virgen, en actitud habitual, como «trono de Dios", sostiene al Niño que en posición nerviosa, bendice al Rey anciano. Los Reyes son tratados de manera individualizada, utilizando el doble sentido icónico: de las edades del hombre y como prefiguración antropológica de tres continentes. Resulta interesante el modelo del Rey adulto que cubre su cabeza con un gorro de época de Felipe II, al que llega incluso a sugerir, y en sus manos sostiene un cofre entreabierto que guarda una rica orfebrería. Son de bellísima traza tanto el cofrecillo, como las ricas copas, propias de modelos germánicos, bien por ser la fuente de inspiración, los repertorios de estampas grabadas, tan utilizadas por Morales, o por copia directa de estos objetos, que no sería difícil encontrar en los tesoros parroquiales de entonces y que comparecen con frecuencia 
en los mencionados grabados y también en pinturas flamencas. Este lujo de detalles trató por igual Morales en las tablas de Plasencia y Arroyo a la que señalamos como antecedente concreto de la de San Martín.

El esquema compositivo evidencia las direcciones de las diagonales que guían las figuras de San José, la Virgen y el Rey viejo por un lado, y la Estrella, el Rey adulto y el Niño por otro. Mientras que la columna profusamente decorada con grutescos en grisalla, sirve para centrar la composición.

Sin duda estamos de nuevo, ante una tabla donde el protagonismo del taller es evidente, con participación escasa de Morales.

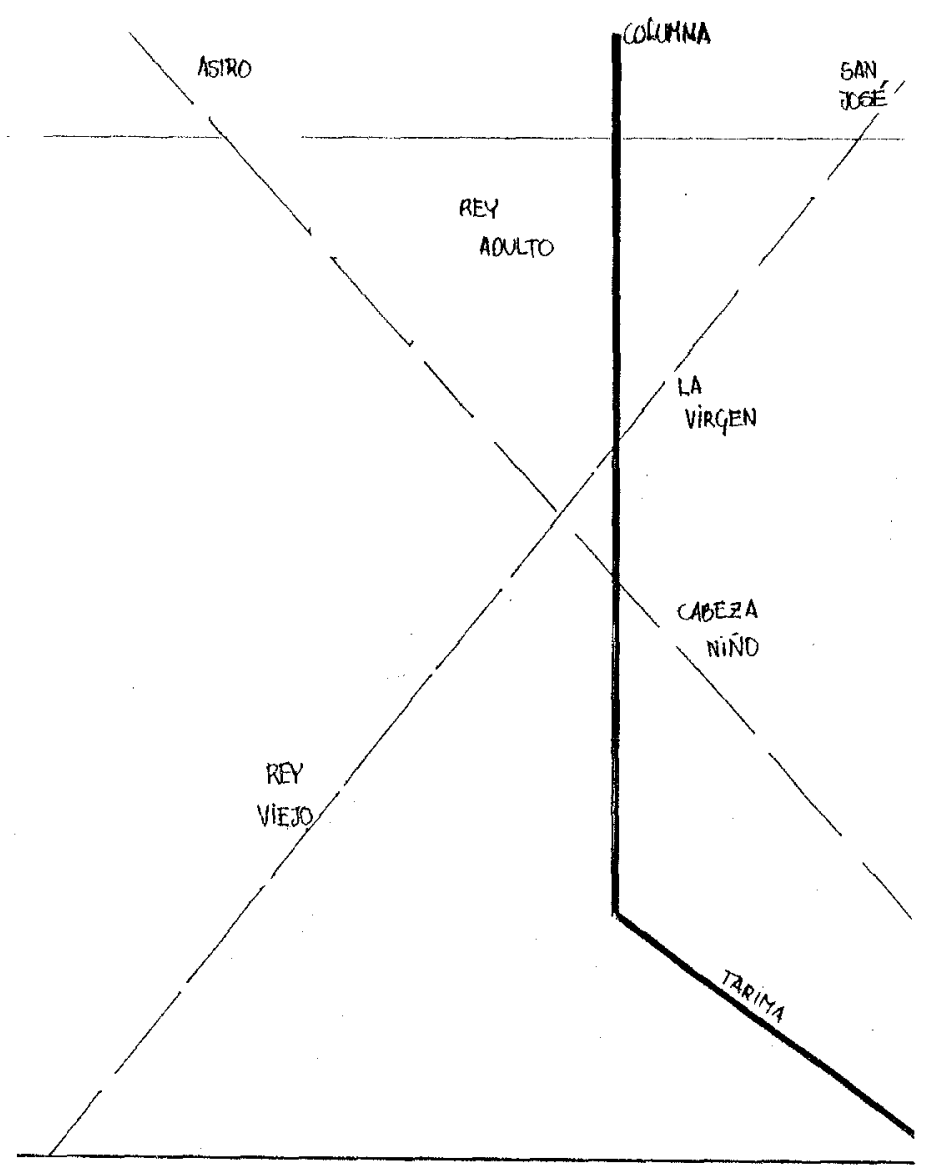

Fig. 7. Esquema compositivo de la Adoración de los Reyes. 


\section{5. «Presentación en el Templo}

Obra estrechamente emparentada, desde el punto de vista de la composición, con las tablas del Museo del Prado y de Arroyo. Las diferencias con esta última son elocuentes. Una mujer con niños en brazos liena en Arroyo el espacio del primer término, que en el cuadro de Plasencia permanece vacío. Sin embargo, es muy parecido el número de personajes en ambas tablas, siendo la de Arroyo más rica en decoración de grutescos que cubre las arquitecturas y el altar, desnudos en San Martín. La figura de la Virgen que contempla el cuerpo del Niño en brazos del Sacerdote Simón, sostiene con la mano izquierda una candela y la derecha la cruza sobre el pecho, siendo visible gracias a la coloración habitual de sus vestidos: túnica gris azulada y tonos carminoso de su manto. San José pasa desapercibido al estar alejado de la Virgen y tras el Sacerdote.

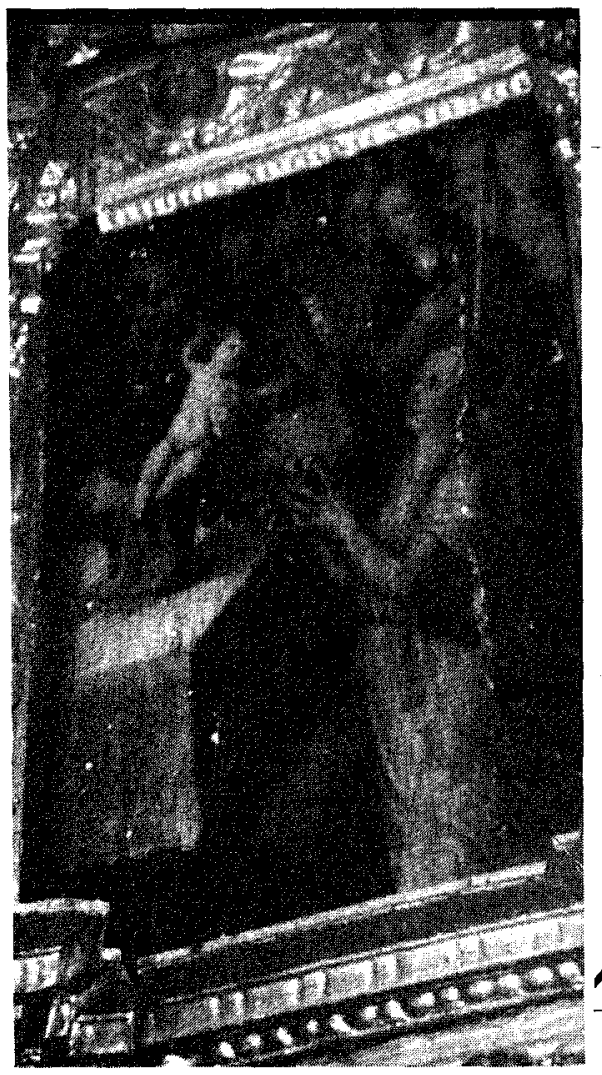

Fig. 8. Presentación en el Templo.

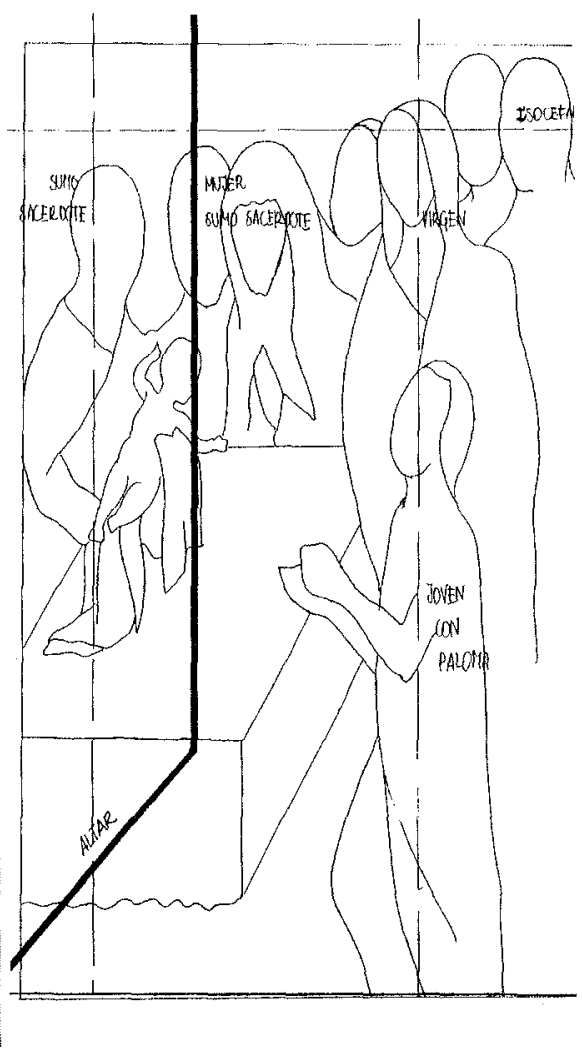

Esquema de la Presentación en el Templo. 
El compacto grupo de espectadores, de tan marcada isocefalia, se aligera únicamente por las diversas actitudes y juegos de miradas.

La composición procede de una estampa de Durero, en las que Morales reduce la perspectiva arquitectónica de la escena a simples objetos simbólicos, al tiempo que le concede el valor costumbrista de la fiesta de las Candelas, tan despreciada por los erasmistas y evangelistas de la España de la época, en opinión de Fernando Marias.

El esquema muestra una composición que se fundamenta en la horizontal isocefálica; aliviada con la diagonal del Sacerdote, el Niño y la doncella con las palomas; y la vertical de esta última doncella con la Virgen.

\section{6. «San Martín y el mendigo»}

El tema le viene impuesto a Morales por ser el Santo patrono de la Iglesia. San Martín es tratado como caballero y no como obispo de Tours,

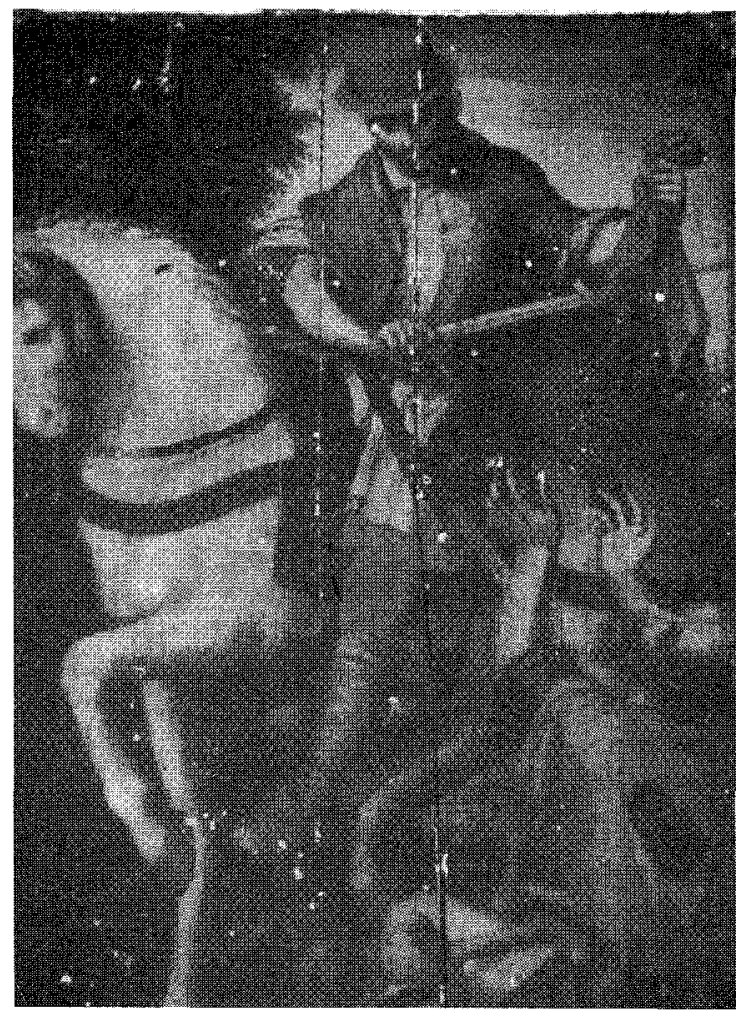

Fig. 9. San Martín. 
por haber sido ya utilizado en la escultura central del retablo, con lo que se completa la dualidad iconográfica del santo/caballero.

San Martín montado a caballo y con vestimenta de época, ofrece parte de su capa al mendigo harapiento que de manera intensa le implora una limosna. Sin duda, las actitudes gesticulares de ambos personajes refuerzan la armonización del grupo. El caballo mantiene unas medidas demasiado convencionales, algo refinadas, pero antinaturales, que nos muestran el lado gótico del pintor.

Existen dos focos de luces diferentes: la que procede del ángulo superior izquierdo y que debemos calificar de «luz divina», auténtico eje vertebral de la obra; y la que proviene del fondo, manifestándose en un extraño contraluz sobre la floresta, de claro efecto leonardesco. El simple esquema compositivo lo fija la diagonal proyectada por los personajes, reforzada por los gestos y“el haz lumínico.

Sin duda, Luis de Morales se vería forzado a utilizar su lenguaje más anacrónico en esta tabla, puesto que debía estar al mismo nivel de percepción que los gustos populares de los demandantes, a los que iba dirigido el retablo, y del que era pieza especial, la representación del santo/patrono de la parroquia de San Martín.

\subsection{Las tablas de la predela}

Se trata de las figuras de los Santos Padres de la Iglesia San Jerónimo y San Agustín. Por lo que debe desmentirse de una vez por todas que se trate de dos pequeñas escenas relacionadas con la vida de San Martín, como se ha venido afirmando en todos los estudios realizados sobre el retablo.

\subsection{1 «San Jerónimo»}

Lleva la cabeza cubierta con el «sombrero cardenalicio», si bien jamás fue cardenal (tan sólo ejerció la función de secretario del Papa Damasco). Para señalar que era hombre de estudios, a partir del siglo xv, le suelen colocar o un Volumen en sus manos o dentro de un escritorio monacal. En el ángulo superior izquierdo se representa al Santo en su faceta de «Penitente», semidesnudo y acompañado del León, al que sacó una espina de la pata. 


\subsection{2. «San Agustín».}

Aparece como obispo, con mitra y báculo. En este caso, lleva en su mano derecha un libro, en alusión a su obra «La ciudad de Dios». El refuerzo sobre el valor ordenador de su pragmática se hace visible con la aparición de un esquema de ciudad ideal, por medio de arquitecturas fantásticas y ambiente reposado de personas que pasean en círculo.

Ambas tablas deben ser atribuidas a su taller, por los vicios pictóricos que en ellas se detectan y el repertorio convencional utilizado.

\section{CONCLUSIONES}

El deseo de sistematizar un análisis de fácil comprensión y difusión de las tablas de Luis de Morales en el Retablo de San Martín de Plasencia es lo que ha dominado en nuestra investigación.

Nos volvemos a encontrar a un Morales, en la etapa culmen de su vida, que abrumado por la cantidad de encargos para la realización de retablos, no duda en utilizar la monotonía temática, el abandono en manos de sus ayudantes y el recurso seriado de las estampas flamencas, alemanas o italianas, reservándose unicamente la pintura de rostros y manos, el toque personal que remata la obra colectiva, donde el artista esconde, y no muestra, su personalidad.

Las tablas fueron realizadas entre los años 1565 y 1570 . Y en la actualidad se mantienen en su sitio original y se conservan, aunque en lamentable estado, en su integridad. 
